\title{
THE EFFECTS OF ICI 46,474 ON OVUM TRANSPORT AND IMPLANTATION IN THE RAT
}

\author{
J. S. MAJOR AND P. J. HEALD \\ Department of Biochemistry, University of Strathclyde, \\ 204 George Street, Glasgow G1 1 XW
}

(Received 16th Fanuary 1973)

\begin{abstract}
Summary. The effects of the non-steroidal, postcoital, antifertility agent, ICI 46,474 , on ovum transport and implantation in the rat have been examined. When administered as a single implantation-inhibiting dose on Day 2 of pregnancy, the compound had only a marginal effect on the transport of ova through the oviduct. After entering the uterus at approximately the normal time, however, $79 \%$ of the eggs were lost by Day 6 . The remaining eggs, while unimplanted, had shed their zonae pellucidae. When animals were treated on Day 2 of pregnancy with a dose of ICI 46,474 which reduced the size of implantation sites observed on Day 9, but which allowed pregnancy to occur, implantation was delayed by some $16 \mathrm{hr}$. It is concluded that ICI 46,474 given on Day 2 of pregnancy is capable of affecting implantation without altering blastocyst transport through the oviduct and it is suggested that alteration of uterine metabolism is the main factor contributing to its antifertility effects in the rats used.
\end{abstract}

The compound ICI 46,474 (trans-1-( $p$ - $\beta$-dimethylamino-ethoxyphenyl)-1-2diphenylbut-l-ene), one of a series of triarylethylenes the synthesis of which was reported by Bedford \& Richardson (1966), has been shown to be an extremely effective postcoital antifertility agent in the rat (Harper \& Walpole, $1967 \mathrm{a}, \mathrm{b})$. When given on Days 1 or 2 of pregnancy at a dose sufficient to prevent implantation completely, the failure to recover ova from the reproductive tract at autopsy on Day 5 led to the suggestion that accelerated passage of the ova through the oviducts and their expulsion from the uterus is sufficient to account for the termination of pregnancy by the compound. When given on Days 3 or 4 , the minimal effective dose was lower than that required on Days 1 or 2, and in the dose required to block implantation completely, neither transport of the eggs through the oviduct nor their development was affected (Harper \& Walpole, 1967b). Indeed, after such treatment, blastocysts were recovered from the uterus in diminishing numbers for at least 7 days, and were regarded as normal from their morphological appearance and from their ability to implant after transfer to the uteri of 5-day pseudopregnant rats (see Walpole, 1968). Inhibition of implantation by doses given on Days 3 or 4 has been ascribed to the antioestrogenic action of ICI 46,474 (Harper \& Walpole, 1967a). 
Previous work in these laboratories using a Holtzman-derived SpragueDawley strain of rats (O'Grady, Heald \& O'Hare, 1970; Reid \& Heald, 1971) has shown that the effective dose of ICI 46,474 necessary on Day 2 was less than that required by previous workers using a Wistar strain (Harper \& Walpole, $1967 \mathrm{a}, \mathrm{b})$. Accordingly, as part of an investigation into the mechanisms of action of ICI 46,474 and other antifertility agents, it was considered necessary to re-examine the effects of this compound on tubal transport of fertilized ova. Since it had also been found (Harper \& Walpole, 1967a; O'Grady et al., 1970) that suboptimal doses led to a decreased size of the implantation site on Day 9 , it was thought possible that the compound might, at such doses, be acting to delay implantation. Examination of both these points is now reported.

\section{METHODS}

The rats used were a Holtzman-derived Sprague-Dawley strain with a 5-day oestrous cycle, bred for the past 5 years as a closed colony from a breeding nucleus supplied by the Holtzman Company, Madison, Wisconsin. They were housed in windowless rooms with a lighting cycle from 06.00 to 20.00 hours GMT and a mean temperature of $22^{\circ} \mathrm{C}$. Food and water was supplied freely. Adult, virgin females were caged with proven males and the morning that spermatozoa were found in the vaginal smear was designated Day 1 of pregnancy. The ICI 46,474 (supplied as the free base) was made up as a dispersion in $0.5 \% \mathrm{w} / \mathrm{v}$ aqueous Tween 80 and was stored in the dark at 4 to $6^{\circ} \mathrm{G}$.

\section{Visualization of implantation sites}

Sites of implantation on Day 6 of pregnancy were visualized by intravenous injection, under ether anaesthesia, of $1.0 \mathrm{ml}$ of a saturated solution of Diamine Blue in $0.9 \%(\mathrm{w} / \mathrm{v}) \mathrm{NaCl}$ given $10 \mathrm{~min}$ before killing the animal (Psychoyos, 1965, 1971). At autopsy, the uteri were trimmed free from fat and examined for the presence of blue bands.

Ovum transport. Animals were treated with a single oral dose of ICI 46,474 $(0.2 \mathrm{mg} / \mathrm{kg})$ on the morning of Day 2 of pregnancy. Control animals received the vehicle alone. Groups of treated and control animals were killed on the morning of Days 4, 5 and 6,10 min after injection of Diamine Blue solution. The body weights, wet weights of the uteri, ovaries and pituitaries were noted, and the number of corpora lutea in the ovaries were recorded. Ova were flushed from the uterine horns and oviducts as described by Dickmann (1971). After flushing, the uteri were dried at $80^{\circ} \mathrm{C}$ for $48 \mathrm{hr}$ for dry matter determination.

\section{Effect of ICI 46,474 on size of implantation sites}

Mated rats were allocated to four groups of five to eight animals and were dosed orally on the morning of Day 2 of pregnancy. Group-1 rats received the vehicle alone, Group-2, -3 and -4 rats received ICI 46,474 at $0.05 \mathrm{mg} / \mathrm{kg}$, $0.1 \mathrm{mg} / \mathrm{kg}$ and $0.2 \mathrm{mg} / \mathrm{kg}$ body $\mathrm{wt}$, respectively. The animals were killed on Day 9 and the implantation sites were dissected and weighed.

Delayed implantation. Animals were treated with a single oral dose of $0.1 \mathrm{mg}$ 


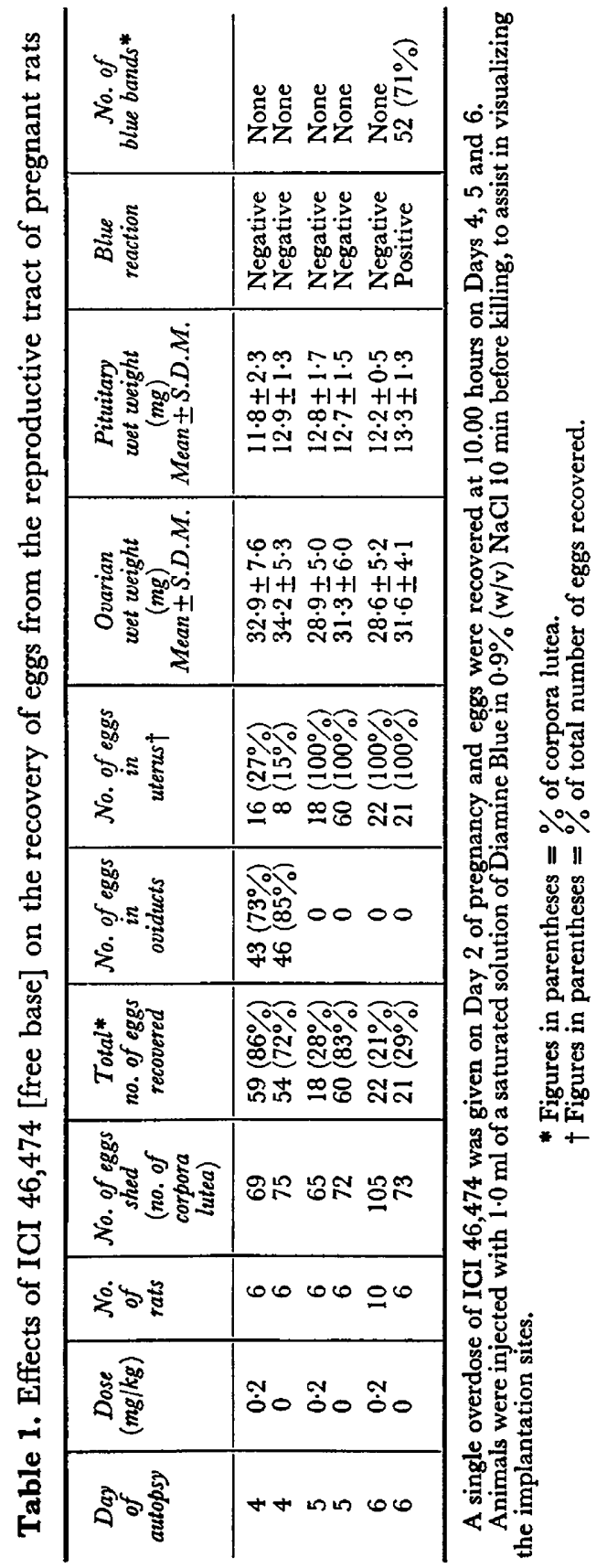


ICI $46,474 / \mathrm{kg}$ on the morning of Day 2 of pregnancy. On Days 5 and 6, implantation sites were visualized as described above. This procedure was carried out at various time intervals between 12.00 and 23.00 hours on Day 5 and between 09.30 and 18.00 hours on Day 6. Groups of control animals were treated in a similar manner, principally on Day 5.

\section{RESULTS}

Initial experiments showed that a dose of $0 \cdot 20 \mathrm{mg}$ ICI $46,474 / \mathrm{kg}$ given on Day 2 was completely effective in suppressing implantation but lower doses of $0 \cdot 1$ and $0.05 \mathrm{mg} / \mathrm{kg}$ were not (Table 1 and Text-fig. 2). At the same time, Table 1 shows that a single oral dose of $0.2 \mathrm{mg}$ ICI $46,474 / \mathrm{kg}$ body weight on Day 2 of pregnancy had only a marginal, if any, effect on transport of the ova through the oviducts. On the morning of Day $4,73 \%$ of the recovered eggs were still in

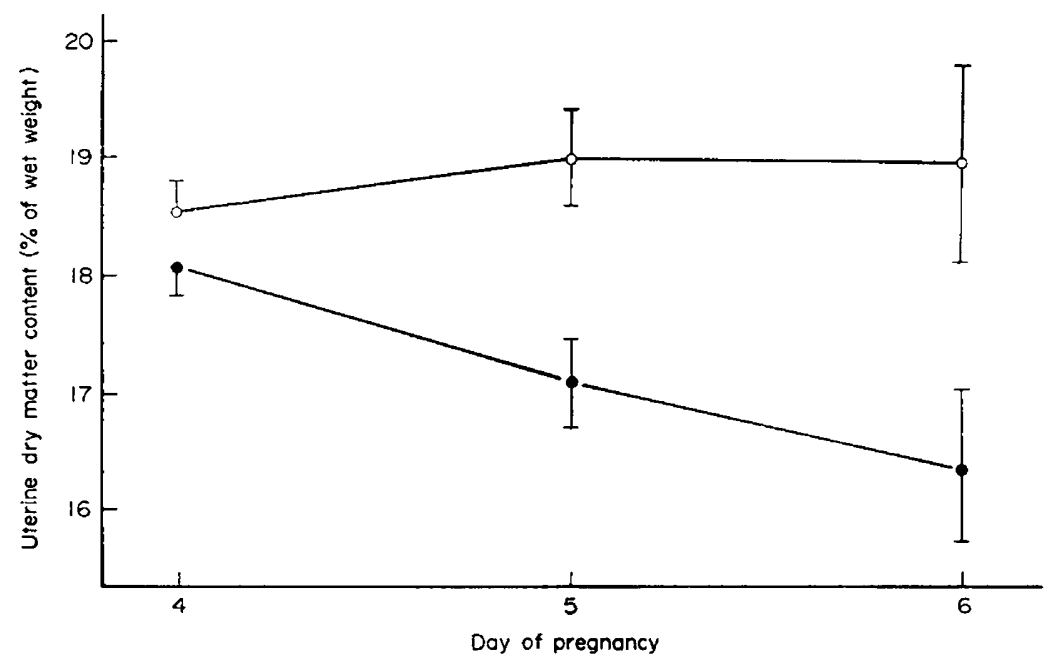

TEXT-FIG. 1. Dry matter content of uteri of pregnant rats receiving $0.2 \mathrm{mg}$ ICI $46,474 / \mathrm{kg}$ orally on Day 2 of pregnancy. $\bullet$, pregnant controls; $O$, animals treated with ICI 46,474 . Vertical bars represent the S.D.M.

the oviducts compared to $85 \%$ in the oviducts of control rats. In both groups, the eggs appeared to be developing normally when examined under the dissecting microscope and phase contrast. In general, the eggs were in the eight-cell to morula stage and had intact zonae pellucidae. On the morning of Day 5, however, only $28 \%$ of eggs shed were recovered from the uteri of treated animals while $83 \%$ could be flushed from the uteri of control animals. Eggs were not recovered from the oviducts of the rats in either group at this time. Microscopic examination of the eggs revealed no apparent difference between those from treated and control animals. All eggs recovered, with the exception of a few unfertilized ova, were in the blastocyst stage, each with a well-defined blastocoele and intact zona pellucida. By the 6th day, only $21 \%$ of eggs shed were recovered from the uteri of treated animals; no eggs were recovered from the oviducts. The blastocysts recovered from treated animals on Day 6, though 


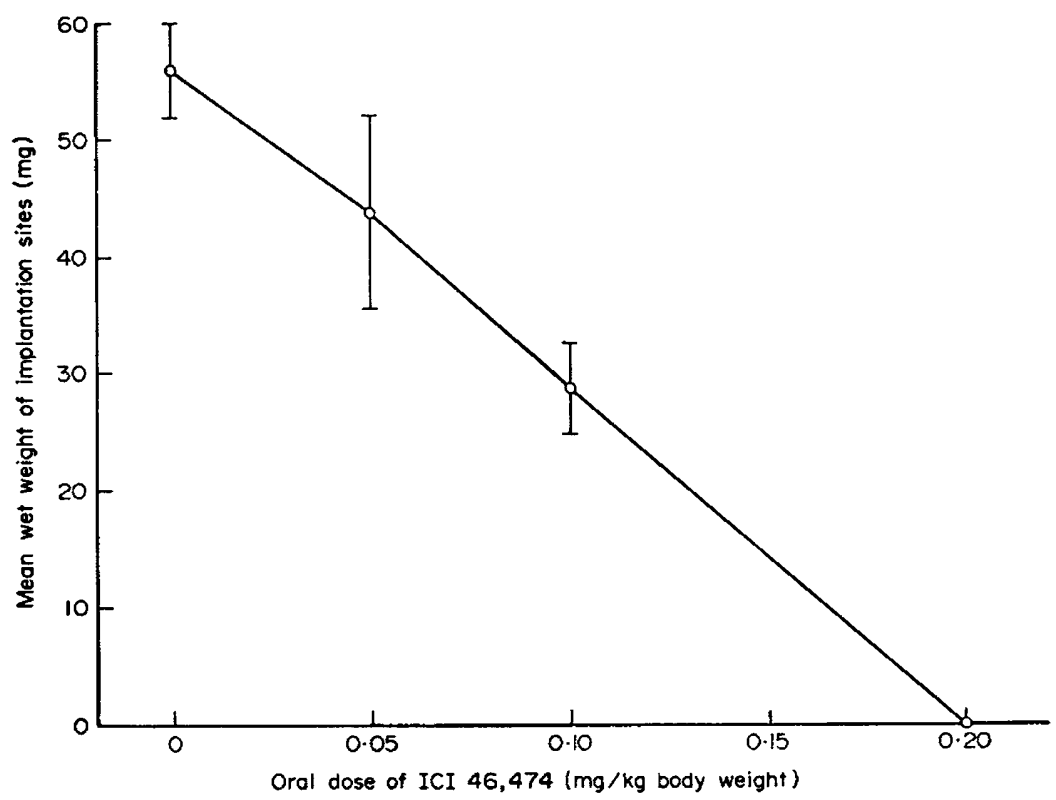

TEXT-FIG. 2. Effect of ICI 46, 474 given on Day 2 of pregnancy on the wet weights of implantation sites measured on Day 9. Vertical bars represent the S.D.M.

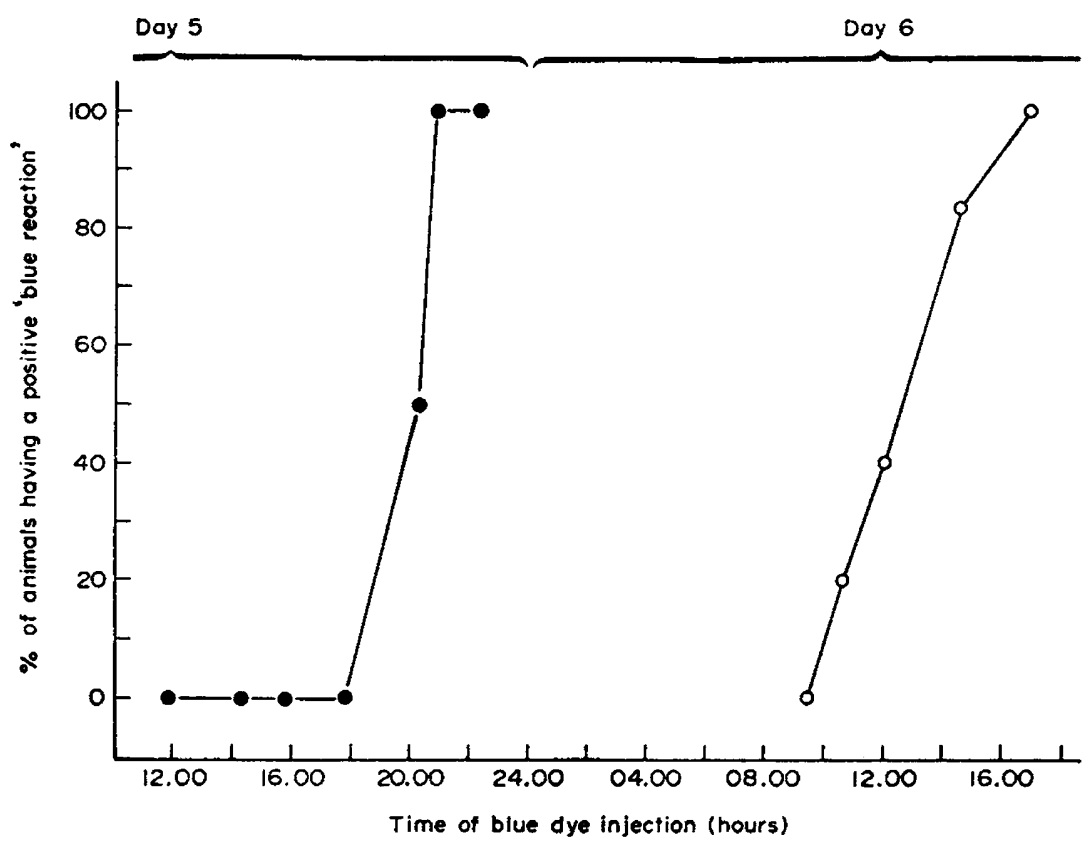

TeXT-FIG. 3. Delay in implantation in pregnant rats induced by $0.1 \mathrm{mg}$ ICI $46,474 / \mathrm{kg}$ orally on Day 2. The onset of implantation was determined by injection of Diamine Blue, $10 \mathrm{~min}$ before killing. $\bullet$, Control animals; $O$, treated animals. Each point represents results from a group of five rats. The mean number of implantation sites in the control group was $9 \cdot 9 \pm 1.4$ (S.D.)/rat, and in the treated group was $6 \cdot 9 \pm 3 \cdot 2$ (S.D.)/rat. 
not implanted, had shed their zonae pellucidae. Since implantation is well under way in control animals by Day 6 , only $29 \%$ of the eggs shed could be recovered, presumably as a result of fairly firm attachment of the remainder to the uterine endometrium. Thus, fifty-two blue bands were observed in the uteri from six animals, a number of presumptive implantation sites corresponding to $71 \%$ of the eggs shed. There was no significant difference in the mean pituitary wet weight or mean ovarian wet weight between control and treated groups at any stage.

Animals receiving $0.2 \mathrm{mg} / \mathrm{kg}$ on Day 2 showed no change in uterine water content on Day 5 in contrast to the untreated controls (Text-fig. 1), the difference being even more marked once implantation had occurred by Day 6 . Insofar as increased water content is associated with oestrogen, the lowered water content in the treated animals is considered to be due to the absence or suppression of oestrogenic stimulation

When animals were treated on Day 2 of pregnancy with $0 \cdot 1 \mathrm{mg} / \mathrm{kg}$ ICI 46,474 , a dose which reduced the size of implantation sites observed on Day 9 (Text-fig. 2) but which allowed pregnancy to occur, the first signs of implantation were delayed for some $16 \mathrm{hr}$ (Text-fig. 3). In control animals, the 'blue reaction' became visible in some rats by about 19.00 hours on Day 5 and was positive in all the animals studied by 21.00 hours. In treated animals, however, the 'blue reaction' did not become visible in some rats until mid-morning on Day 6. By 17.00 hours, there was a positive 'blue reaction' in all the rats studied at this time.

\section{DISGUSSION}

The present data show that when administered in the minimal fully effective dose of $0.2 \mathrm{mg} / \mathrm{kg}$ on Day 2 of pregnancy to the strain of rats used in these experiments, ICI 46,474 did not affect the transport of ova through the oviduct. Consequently, accelerated tubal transport and premature expulsion of eggs into the uterus cannot be the basis for the antifertility properties of the compound in the rats. This result is different from that previously reported in the case of the Wistar strain used by Harper \& Walpole (1967b). After entering the uterus, however, a proportion of eggs appeared to be lost by Day 5 , perhaps indicating some malfunction in the mechanism involved in spacing the blastocysts regularly along the uterine horn. Clearly, since no ova were recovered from the oviducts after Day 4, tubal retention of eggs cannot be the cause of the decreased number of blastocysts found in the uterus on Day 5. Since retention and spacing is believed to be brought about by muscular activity in the myometrium, itself dependent on the oestrogen-progesterone environment, it is possible that the ICI 46,474 , by modifying the oestrogen-progesterone balance, might alter the muscular activity with the resultant expulsion of eggs through the vagina. Though not established for ICI 46,474 , it is relevant in this connection that the non-steroidal oestrogen antagonist CN-55,945-27 (1-\{2-(p$[\alpha(p$-methoxyphenyl)- $\beta$-nitrostyryl $]$ phenoxy)ethyl $\}$ pyrolidine, monocitrate) has been found to alter the electrical and mechanical properties of rat myometrium measured in vitro (Marshall \& O'Brien, 1967). It has been shown that ICI 46,474 is not zygotoxic and since blastocysts were found in the uterus on Days 5 
and 6 in treated animals yet remained unimplanted, it is considered that ICI 46,474 must affect the implantation process itself either directly or indirectly. The observed delay in implantation brought about by a sub-maximal dose of ICI 46,474 supports this belief.

The precise mechanism of action at the uterine level is still undefined. It has been shown (Skidmore, Walpole \& Woodburn, 1972) that the compound is antioestrogenic, being a competitive inhibitor of the uptake of oestradiol-17 $\beta$ by oestrogen receptors in the uterine cytosol and that the inhibition of implantation in the rat can be partly reversed by large doses of oestradiol given by Day 4 (Harper \& Walpole, 1967b). If the action is primarily that of preventing the uterine response to oestrogen, the differential effect of the two doses reported in this work might be ascribed to the fact that by Day 6 the lower dose had been cleared from the uterine sites permitting implantation to occur.

The higher dose, in addition to assisting uterine expulsion of the blastocysts, might presumably remain at the uterine receptor sites for a length of time sufficient to prevent any possibility of response of the uterus to the presumed oestrogen surge. In this connection, however, the delay in implantation obtained with the lower dose of ICI 46,474 presents an interesting problem. It has been widely held (see review by DeFeo, 1967), with some experimental support (Shaikh \& Abraham, 1969; Shaikh, 1971), that the implantation of the blastocyst is initiated by a release of ovarian oestrogen principally on Day 4 of pregnancy in the rat, and that this release is completed by Day 5. Alternative evidence (DeFeo, 1967; Miller, Owen \& Emmens, 1968; Nimrod, Ludany \& Lindner, 1972) suggests that oestrogen is released continuously from Day 2 of pregnancy with no sudden release on Day 4. The effect of ICI 46,474 in delaying implantation is more in keeping with this latter view rather than the former since it is not easy to see at this time how a release of oestrogen confined to the afternoon of Day 4 would initiate implantation some $48 \mathrm{hr}$ later. Other possibilities exist, however, such as involving interaction of ICI 46,474 at the ovary and pituitary (J. S. Major and P. J. Heald, unpublished work).

It is apparent from these results that ICI 46,474, given on Day 2 of pregnancy, is capable of affecting implantation without altering blastocyst transport through the oviduct and it is suggested that alteration of uterine metabolism is the main factor contributing to its antifertility effects in the present strain of rats.

\section{ACKNOWLEDGMENTS}

We thank the Science Research Council for a CAPS award to Mr John Major and Dr A. L. Walpole, ICI Pharmaceuticals Division, for gifts of chemicals.

\section{REFERENCES}

Bedford, G. R. \& Richardson, D. N. (1966) Preparation and identification of cis and trans isomers of a substituted triarylethylene. Nature, Lond. 212, 733.

DeFeo, V. J. (1967) Decidualisation. In: Gellular Biology of the Uterus, p. 191. Ed. R. M. Wynn. North Holland Publishing Go., Amsterdam.

Dickmann, Z. (1971) Egg transfer. In: Methods in Mammalian Embryology, p. 133. Ed. J. G. Daniel, Jr. Freeman, San Francisco.

Harper, M. J. K. \& Walpole, A. L. (1967a) A new derivative of triphenylethylene: effect on implantation and mode of action in rats. $\mathcal{F}$. Reprod. Fert. 13, 101. 
HARPER, M. J. K. \& WALPOLE, A. L. (1967b) Mode of action of ICI 46,474 in preventing implantation in rats. F. Endocr. $37,83$.

Marshall, J. M. \& O'Brien, O. P. (1967) Action of an estrogen antagonist on the electrical and mechanical properties of the rat uterus in vitro. Endocrinology, 80, 747.

Miller, B. G., OwEN, W. H. \& Emmens, G. W. (1968) Uridine incorporation in the rat genital tract during early pregnancy. F. Endocr. 42, 35.

Nimrod (Zmigrod), J. A., Ludany, S. \& Lindner, H. R. (1972) Perinidatory ovarian oestrogen secretion in the pregnant rat determined by gas chromatography with electron capture detection. $\mathcal{F}$. Endocr. 53, 249.

O'Grady, J. E., Heald, P. J. \& O'JfAre, A. (1970) Incorporation of $\left[{ }^{3} \mathrm{H}\right]$ uridine into the ribonucleic acid of rat uterus during pseudopregnancy and in presence of IGI 46,474 [trans-1-( $p$ - $\beta$-dimethylaminoethoxyphenyl)-1,2-diphenylbut-1-ene]. Biochem. F. 119, 609.

Psychoyos, A. (1965) Côntrole de la nidation chez les mammifères. Archs Anat. microsc. morph. exp. 54, 85.

Psychoyos, A. (1971) Methods for studying changes in capillary permeability of the rat endometrium. In: Methods in Mammalian Embryology, p, 334. Ed. J. C. Daniel, Jr. Freeman, San Francisco.

Reid, R. J. \& Heald, P. J. (1971) Protein metabolism of the rat uterus during the oestrous cycle, pregnancy and pseudopregnancy, and as affected by an anti-implantation compound, ICI 46,474. F. Reprod. Fert. 27, 73.

Shaikh, A. A. (1971) Estrone and estradiol levels in the ovarian venous blood from rats during the estrous cycle and pregnancy. Biol. Reprod. 5, 297.

Shaikh, A. A. \& Abraham, G. E. (1969) Measurement of estrogen surge during pseudopregnancy in rats by radioimmunoassay. Biol. Reprod. 1, 378.

Skidmore, J., WALPOLE, A. L. \& WoodBuRn, J. (1972) Effect of some triphenyl ethylenes on oestradiol binding in vitro to macromolecules from uterus and anterior pituitary. 7. Endocr. 52, 289.

WALPOLE, A. L. (1968) Non-steroidal drugs in relation to ovulation and implantation. F. Reprod. Fert., Suppl. 4, 3. 